\title{
Rightward Incrementality in Encoding Simple Phrasal Forms in Speech Production: Verb-Particle Combinations
}

\author{
Ardi Roelofs \\ Max Planck Institute for Psycholinguistics
}

\begin{abstract}
This article reports 7 experiments investigating whether utterances are planned in a parallel or rightward incremental fashion during language production. The experiments examined the role of linear order, length, frequency, and repetition in producing Dutch verb-particle combinations. On each trial, participants produced 1 utterance out of a set of 3 as quickly as possible. The responses shared part of their form or not. For particle-initial infinitives, facilitation was obtained when the responses shared the particle but not when they shared the verb. For verb-initial imperatives, however, facilitation was obtained for the verbs but not for the particles. The facilitation increased with length, decreased with frequency, and was independent of repetition. A simple rightward incremental model accounts quantitatively for the results.
\end{abstract}

Skilled behavior such as speech production requires advance planning of action components (e.g., Lashley, 1951). In the present paper, I examine what mode the speech production system uses in planning the morphophonological form of an utterance. In particular, I investigate whether the speech production system plans the form of an utterance in a parallel or in a rightward incremental fashion. Planning the production of speech proceeds incrementally if an encoding stage is initiated by a critical fragment of the output of a preceding stage rather than by its complete output (e.g., Kempen \& Hoenkamp, 1987; Levelt, 1989). For example, incrementality means that the process of syllabification in form encoding starts when it receives the initial segments of the intended utterance. The process does not wait until all the segments of the utterance have been made available. Planning the production of speech proceeds in a rightward fashion if an utterance is planned from the beginning to its end rather than in parallel or from the end to the beginning.

Empirical evidence suggests that the planning of speech occurs at a number of levels. Three major types of processes are typically assumed to underlie language production: conceptualization, formulation, and articulation (Butterworth, 1980; Dell, 1986; Garrett, 1975, 1988; Kempen \& Hoenkamp, 1987; for recent reviews, see Caplan, 1992, Bock \& Levelt, 1994, and especially Levelt, 1989). Conceptualization processes map a communicative intention onto a message, indicating which conceptual information has to be

Ardi Roelofs, Max Planck Institute for Psycholinguistics, Nijmegen, The Netherlands.

I am grateful to Maarten van Casteren for his help in preparing the experiments and running them and to Antje Meyer, Pim Levelt, Linda Wheeldon, and Kay Bock for helpful comments.

Correspondence concerning this article should be addressed to Ardi Roelofs, who is now at the Department of Psychology, University of Exeter, Washington Singer Laboratories, Perry Road, Exeter EX4 4QG United Kingdom. Electronic mail may be sent to a.roelofs@ex.ac.uk. expressed verbally to reach a speaker's communicative goal. A message makes explicit the intended lexical concepts and their relationships, among other things (cf. Roelofs, 1997a). Next, formulation processes retrieve words for the lexical concepts (this process is called lexical access) and plan a syntactic structure and a morphophonological structure. The final result is an articulatory program (phonetic plan) for the utterance. Articulation processes execute the articulatory program, which results in overt speech.

In the theoretical framework that I adopt in this article, lexical access is assumed to consist of two major steps, called lemma retrieval and word-form encoding (e.g., Kempen \& Huijbers, 1983; Levelt, 1989, 1992). These two accessing steps are part of the two formulation stages, syntactic and morphophonological encoding, respectively. In conceptually driven lemma retrieval, a lexical concept is used to recover the lemma of the corresponding word from memory. A lemma is a memory representation of the syntactic properties of a word (Kempen \& Hoenkamp, 1987; Levelt, 1992; Roelofs, 1992a, 1993, 1996a). For example, a verb lemma specifies the word's syntactic class (verb) and its valency (i.e., what kind of complements the verb takes, such as direct and indirect object), among other things. A verb lemma also contains a number of abstract morphosyntactic parameters for the specification of tense and agreement (e.g., tense: present, past; number: singular, plural; person: first, second, third) and for the specification of the verb's mood (e.g., infinitive, imperative). Setting these parameters provides an index to a form pointer. The lemma retrieval process delivers this pointer to the subsequent processes that recover the word's morphophonological properties from the mental lexicon and encode the form of the word. The memory representation of these form properties is sometimes called the word's lexeme (e.g., Kempen \& Huijbers, 1983).

Although some theories have explicitly adopted the assumption of rightward incrementality for these planning processes (e.g., Dell, 1986; Levelt, 1989), direct empirical evidence for several aspects of this claim is hard to come by. 
Parallelism seems to be a valid alternative approach to language production. For example, according to Stemberger (1985b), speech error "evidence suggests that all of the words in a clause and all the segments of a word are selected at the same time" (p. 274). In this view, fragments of an utterance are planned simultaneously rather than from left to right. Whereas proposals of rightward incrementality have been developed to the point that they could be computationally implemented and several precise quantitative predictions could be tested (e.g., Dell, 1986; Roelofs, 1994, 1996b, 1996 c, 1997b, 1997c; Roelofs \& Meyer, in press), this does not hold for the alternative of full parallelism.

The speech-error evidence for parallel planning concerns failures in the serial ordering of elements. These elements are typically words, morphemes, or segments. Speech errors that concern a misordering of elements within an utterance (called contextual or plan-internal errors) suggest that the planning occurs at a number of levels and that the planning of the elements within a level overlaps in time. The support for parallel encoding at a lemma level as distinct from a lexeme level concerns the different distribution of word and segment exchanges. Word exchanges such as the swapping of roof and list in "we completely forgot to add the list to the roof" (from Garrett, 1980) typically concern elements from different phrases and of the same syntactic category (here noun). By contrast, segment exchanges such as the interchange of the $/ \mathrm{p} /$ and $/ \mathrm{r} /$ in "she's a real rack $p$ at" (from Garrett, 1988) typically concern elements from the same phrase and do not respect lexical category. These findings can be explained as selection errors during the parallel planning of lemmas in syntactic encoding and the parallel planning of segments in word-form encoding.

Speech errors also provide support for parallel encoding of concrete morphemes at a lexeme level of planning that is distinct from a lemma level with abstract morphosyntactic parameters. Some morphemic errors seem to concern the lemma level, whereas others involve the lexeme level, as has been argued by Dell (1986) and Garrett (1975, 1980, 1988), among others. For example, in "how many pies does it take to make an apple?" (from Garrett, 1988), the interacting stems belong to the same syntactic category (i.e., noun) and come from distinct phrases. Note that the plurality of apple is stranded, that is, it is realized on pie, which suggests that an abstract morphosyntactic parameter has to be set for these words. It has been argued that the distributional properties of these morpheme exchanges are similar to those of wholeword exchanges. This suggests that these morpheme errors and whole-word errors occur at the same level of processing, namely when simultaneously planned lemmas in a developing syntactic structure trade places. By contrast, the exchanging morphemes in an error such as "slicely thinned" (from Stemberger, 1985b) belong to different syntactic categories (adjective and verb) and come from the same phrase, which is also characteristic of segment exchanges. This suggests that this second type of morpheme error and segment errors occur at the same level of processing, namely the level at which lexemes are retrieved and the morphophonological form of the utterance is planned. The errors occur when morphemes or segments in a developing form structure are planned at the same moment in time and trade places.

The speech error argument for parallel encoding is not, however, entirely convincing. First, speech errors are rare events. By definition, speech errors reflect unusual circumstances that cannot straightforwardly be taken to represent the norm. It may be possible that speakers normally do not plan a form in parallel and start to make errors when they occasionally try to do so. Thus, it is unclear whether parallel planning in itself is the cause of the error. If it is the cause of the error, this would imply that planning normally does not proceed in a parallel fashion, exactly contrary to the claim of parallelism. For example, speakers might normally encode consecutive words sequentially (cf. Dell, 1986) and might make errors such as "rack pat" for "pack rat" when they occasionally try to spell out simultaneously the segments of successive words (i.e., when they try to spell out $/ \mathrm{p} /$ and $/ \mathrm{r} /$ simultaneously rather than $/ \mathrm{p} /$ first and later $/ \mathrm{r} / \mathrm{s}$. Second, although speech errors may bear on the representation of information in speech production, they do not really reveal much about the time course of planning (cf. Meyer, 1992). For example, the error "slicely thinned" does not reveal whether the base thin is encoded before, simultaneously with, or after the affix - $l y$. The question of whether components of utterances are planned in parallel asks for an approach using a chronometric technique. In recent years, researchers have started to use such techniques and have collected latency data on production. These findings (i.e., Meyer, 1990, 1991; Meyer \& Schriefers, 1991) seem to support rightward incrementality rather than full parallelism, as I argue below.

Third, the argument from speech errors for parallelism served more to counter claims of strict seriality than to provide evidence for parallel planning. The errors do not uniquely support parallelism but can also be explained under certain rightward incremental modes of planning, for example, such as embodied in the recently developed WEAVER + + model of speech production (Roelofs, 1992b, 1996c, 1996d, 1997c; Roelofs \& Meyer, in press; Roelofs, Meyer, \& Levelt, 1996). This computational model recognizes the insights from speech errors but has specifically been designed to provide a unifying account of the increasing body of chronometric data about speech production. The model covers both lemma retrieval and word-form encoding. The word-form encoding part of the model is called WEAVER (Word-form Encoding by Activation and VERification), and the full model including lemma retrieval is called WEAVER ++ .

WEAVER ++ integrates a spreading-activation based lexical network with a parallel system of production rules. Activation of nodes in the network triggers procedures that select lemmas and incrementally build phonetic plans. Upon activation of a node, an associated procedure verifies the links between the node and the selected nodes one level up in the network. Lemma retrieval procedures select the lemma node linked to the target lexical concept node. Morphological encoding procedures select the morpheme nodes that encode a selected lemma node and its tense, agreement, and mood parameters. Phonological encoding 
procedures select the segment nodes linked to the morpheme nodes and serially syllabify the segments in order to construct phonological word representations. These representations specify the syllables and the stress pattern. Finally, phonetic encoding procedures select syllable-based articulatory programs that encode the phonological words.

In WEAVER + + seriality holds for the operation of certain procedures but not for the activation of nodes in the lexical network. The procedures give rise to rightward incrementality, but the morpheme and the segment nodes of a word are activated in parallel (cf. Dell, 1986). The parallel activation of elements in memory allows the model to account for the speech-error evidence (Roelofs, 1996d, 1997c), while the serial operation of procedures explains the chronometric evidence for rightward incrementality. For example, the different distribution of word and segment exchanges is explained by parallel activation of lemma nodes in the network during syntactic encoding and parallel activation of segments during word-form encoding, but does not require full parallel planning. Node selection by the procedures, as opposed to node activation, does not have to occur simultaneously.

Rightward incrementality in WEAVER ++ arises from a suspend-resume mechanism. The three encoding stages (morphological, phonological, and phonetic encoding) compute aspects of an utterance in parallel from the beginning to its end. For example, syllabification can start as soon as the first few segments are available. The resulting partial representation can be buffered until the missing segments are available and syllabification can continue. Thus, when given partial information, computations are completed as far as possible, after which they are put on hold. When given further information, computations continue from where they stopped.

\section{Rightward Incrementality in Encoding Simple Words}

Chronometric evidence for rightward incrementality rather than full parallelism comes from picture-word interference experiments. Meyer and Schriefers (1991) tested for seriality in speech planning by examining the effect of spoken distractor words on object naming. The experiments were conducted in Dutch. The target and distractor words were either monomorphemic monosyllables or disyllables. The monosyllabic targets and distractors shared either the syllable onset and nucleus (begin related) or the nucleus and coda (end related). For example, participants had to name a pictured bed (i.e., they had to say bed, (bet/) while the distractor was bek (/bek/, begin related; beak) or pet (/pet/, end related; cap). Unrelated control conditions were created by recombining pictures and distractors. The disyllabic targets and distractors shared either the first syllable (begin related) or the second syllable (end related). For example, the participants had to name a pictured table (i.e., they had to say tafel /ta-fal/) while the distractor was tapir (/ta-pir/, begin related; tapir) or jofel (/jo-fəl/, end related; pleasant). Distractors were presented just before (i.e., -300 or -150 $\mathrm{ms}$ ), simultaneously with, or right after (i.e., $150 \mathrm{~ms}$ ) picture onset.
The naming latencies were faster with related distractors than with unrelated ones. The difference between begin and end overlap for both the monosyllables and the disyllables was in the stimulus onset asynchrony (SOA) at which the facilitatory effect first appeared. In the begin condition the effect was first detected at SOA $=-150 \mathrm{~ms}$, whereas in the end condition it was first detected at $\mathrm{SOA}=0 \mathrm{~ms}$. With both begin and end overlap the facilitatory effect was still present at the SOA of $150 \mathrm{~ms}$.

The SOA difference supports the assumption of serial encoding of word forms. Simply put, if later segments of an utterance are selected later, the onset of the facilitation should also be later. Computer simulations have shown that WEAVER ++ accounts for the findings (Roelofs, 1994, 1997c). With begin overlap, the model predicts for SOA = $-150 \mathrm{~ms}$ a facilitatory effect of $-29 \mathrm{~ms}$ for the monosyllables (the real effect was $-27 \mathrm{~ms}$ ) and a facilitatory effect of $-28 \mathrm{~ms}$ for the disyllables (real: $-31 \mathrm{~ms}$ ). In contrast, with end overlap, the effect for $\mathrm{SOA}=-150 \mathrm{~ms}$ was $-3 \mathrm{~ms}$ for the monosyllables (real: $-12 \mathrm{~ms}$ ) and $-4 \mathrm{~ms}$ for the disyllables (real: $10 \mathrm{~ms}$ ). With both begin and end overlap, the facilitation was present at the SOAs of 0 and $150 \mathrm{~ms}$.

Evidence for rightward incrementality has also been obtained with another chronometric paradigm. Meyer (1990, 1991) tested for seriality in speech planning using the implicit form-priming paradigm. In this paradigm, speakers have to produce words from learned paired-associates. The big advantage of this paradigm compared with the more widely used picture-word interference paradigm is that the responses do not need to be names of depictable entities, which puts fewer constraints on the selection of materials. In Meyer's experiments, Dutch participants first learned small sets of three or four prompt-response word pairs such as blad-tafel and dier-tapir (top-table and animal-tapir). During the following test phase, they had to say the response word of a pair (e.g., tafel) upon visual presentation on a computer screen of the prompt word (blad). The instruction was to respond as quickly as possible without making mistakes. On each trial, one of the prompts was presented. The order of prompts across trials was random. The production latency, the interval between prompt onset and speech onset, was the main dependent variable. Each experiment comprised two types of sets, called homogeneous and heterogeneous sets. In a homogeneous set, the response words shared part of their form and in a heterogeneous set they did not. For example, the responses shared the first syllable (TAfel, TApir) or the second syllable (taFEL, joFEL) or they were unrelated (tapir, jofel). The same promptresponse pairs were tested in the homogeneous and heterogeneous condition. Only their combinations into sets differed. Meyer found shorter production latencies in homogeneous than in heterogeneous sets. However, this difference was obtained only when the overlap was from the beginning of the responses onward. Thus, facilitation was obtained for the set that included TAfel and TApir but not for the set that included taFEL and joFEL. Furthermore, the strength of the priming effect increased with the number of shared initial segments.

According to WEAVER ++ , this seriality phenomenon 
directly reflects the suspend-resume mechanism that underlies the incremental planning of an utterance. Assume the response set consists of tafel, tapir, and so forth (i.e., the first syllable is shared). Before the beginning of a trial, the morphological encoder can do nothing, the phonological encoder can construct the first phonological syllable (ta) and the phonetic encoder can recover the first motor program [ta]. When the prompt blad is given, the morphological encoder will retrieve $\langle$ tafel $\rangle$. Segmental spellout makes available the segments of this morpheme, which includes the segments of the second syllable. The phonological and phonetic encoders can start working on the second syllable. In the heterogeneous condition (tapir, jofel, etc.), nothing can be prepared. There will be no morphological encoding, no phonological encoding, and no phonetic encoding. In the end-homogeneous condition ( $t a f e l$, jofel, etc.), nothing can be done either. Although the segments of the second syllable are known, the phonological word cannot be computed because the segments that remain to be encoded are to the left of the suspension point (the point at which encoding stopped and waited for new input). In WEAVER ++ , this means that the syllabification process has to go to the initial segments of the word, which amounts to restarting the whole process. Thus, facilitation will be obtained for the homogeneous condition relative to the heterogeneous condition for the begin condition only.

Computer simulations supported this theoretical analysis (Roelofs, 1994, 1997c). Advance knowledge about a syllable was simulated by completing the phonological and phonetic encoding of the syllable before the beginning of a trial. For the begin condition, the model yielded a facilitatory effect of $-43 \mathrm{~ms}$ (real: $-49 \mathrm{~ms}$ ), whereas for the end condition it predicted an effect of $0 \mathrm{~ms}$ (real: $5 \mathrm{~ms}$ ).

The results of implicit priming and the explicit priming in picture-word interference experiments are different in an interesting way. In implicit priming experiments, the production of a disyllabic word like tafel is speeded up by advance knowledge about the first syllable (ta) but not by advance knowledge about the second syllable $(\mathrm{fel})$. In contrast, when first-syllable or second-syllable primes are presented during the production of a disyllabic word, both primes yield facilitation. The difference between begin and end overlap concerns the SOA at which the facilitation first appears. According to WEAVER ++ , both first-syllable and secondsyllable spoken primes yield facilitation, because they will lead to activation of segments of the target word in memory and therefore speed up its encoding. The SOA difference reflects the rightward syllabification of segments by the application of production rules. Implicit priming reflects the rightward syllabification only. Thus, later syllables cannot be prepared before earlier ones.

WEAVER++'s distinction between activation of elements in memory and the serial application of production rules predicts that implicit and explicit primes yield independent effects. This has been tested in experiments combining homogeneous and heterogeneous response sets (the implicit primes) with form-related and form-unrelated spoken distractors (the explicit primes; Roelofs, 1998). For example, participants had to produce words like tafel. In homoge- neous sets, the responses shared the first syllable (e.g., $t a$ in tafel). The spoken distractors consisted of the final syllables of the utterance, either a target syllable (e.g., fel for tafel, the related condition) or a syllable of another item in the response set (the unrelated condition). The homogeneity variable and the distractor variable yielded main effects and the effects were additive, as predicted by WEAVER ++ .

\section{Rightward Incrementality in Encoding Complex Words}

WEAVER + + operates in a rightward incremental fashion at both the segmental and the morphological level. Morphological structure must be made explicit by the lexical entries in the model, because morphemes define domains of syllabification (Booij, 1995). For example, without morphological structure, the $/ \mathrm{r} /$ of the prefix ver- of vereisen (demand) would incorrectly be syllabified with the base eisen (following the maximal onset principle in syllabification, e.g., Goldsmith, 1990) rather than correctly with the prefix ver-.

Roelofs (1996c) used the implicit priming paradigm to test for rightward incrementality at the morphological level. WEAVER + + predicts that a larger facilitatory effect should be obtained when shared initial segments constitute a morpheme than when they do not. For example, the effect should be larger for sharing the syllable $b i j$ in response sets including Dutch compounds such as bijrol (morphemes (bij) and (rol), supporting role) than for sharing the syllable bij in sets including simple words such as bijbel (morpheme (bijbel), bible). For monomorphemic words like bijbel consisting of the morpheme (bijbel), sharing the first syllable $b i j$ allows phonological preparation only. In contrast, for polymorphemic words like bijrol consisting of the morphemes 〈bij) and (rol), additional morphological facilitation should be obtained if morphemes are planned from left to right, just like the syllabification of segments. Seriality also implies that it should be impossible to prepare noninitial morphemes, such as $\langle\mathrm{rol}\rangle$ in bijrol.

The outcomes confirmed the predictions. More facilitation was obtained when a shared initial syllable constituted a morpheme than when it did not. For example, the effect was larger for bij in bijrol ((bij) and $\langle\mathrm{rol}\rangle$ ) than for bij in bijbel ((bijbel)). WEAVER++ predicted $61 \mathrm{~ms}$ (real: $74 \mathrm{~ms}$ ) facilitation when the syllable constituted a morpheme and 43 ms (real: $30 \mathrm{~ms}$ ) when it did not. In the experiments, no facilitation was obtained for sharing noninitial morphemes, as predicted. For example, no effect was obtained for $\langle\mathrm{rol}\rangle$ in bijrol. Similarly, in producing prefixed verbs, facilitation was obtained for the prefix but not for the noninitial base. For example, facilitation was observed for the prefix $\langle\mathrm{be}\rangle$ of behalen (obtain), but not for the base halen.

\section{Rightward Incrementality in Encoding Phrases and Sentences}

Meyer (1996) examined the span of advance planning in producing phrases and sentences. She asked Dutch participants to describe pairs of pictured objects using spoken 
phrases or sentences. For example, in referring to a picture of a star that stood next to a wheel, they had to produce the noun phrase conjunction "de ster en het wiel" ("the star and the wheel") or the sentence "de ster staat naast het wiel" ("the star is next to the wheel"). Meyer presented spoken distractor words that were either semantically related to the first or second noun to be produced, maan (moon) for ster and band (tire) for wiel, or phonologically related to the first or second noun, stem /stem/ for ster/ster/ and wieg /wig/ for wiel /wil/. The effects of these related distractors were compared with the effect of unrelated distractors. Meyer obtained a semantic inhibition effect for both the first and second noun, but a phonological facilitation effect for the first noun only.

These results suggest that before speech onset the lemma but not the form of the second target noun needs to be selected. Similar to what Schriefer's (1992) results suggest for adjective-noun phrases, the lemmas of both nouns in the noun phrase conjunctions and sentences seem to be retrieved in parallel. Meyer's findings suggest that the initiation of articulation does not require that the phonetic plan for the second noun be complete. On the basis of these findings, Meyer argued that the syntactic planning unit is larger than the morphophonological one. Her findings are consistent with the speech error evidence about the distribution of word and segment exchanges, which demonstrated that speakers use larger planning units at the syntactic than at the morphophonological level. Concerning the seriality issue, the results are compatible with both rightward incremental and parallel planning at the form level. The findings imply that in order to initiate articulation, form encoding for the first noun has to be finished, but they leave open whether the form of the second noun is computed in parallel or later. Adopting the planning spans proposed by Meyer (1996), WEAVER + + predicts semantic inhibition for both the first and second noun and phonological facilitation for the first noun only (Roelofs, 1992a, 1992b, 1996d), as empirically observed.

In summary, speech errors have been taken to support parallel planning of speech. However, the rightward incrementality of the WEAVER ++ model is also compatible with the error evidence and makes correct predictions about the time course of form encoding. The experiments in the present article will serve not only the general purpose of gaining further evidence about the mode of speech planning, parallel or rightward incremental, but also to test the WEAVER ++ model. In examining the mode of planning, the article concentrates on Dutch verb-particle combinations.

\section{Verb-Particle Combinations}

Dutch, like German, Afrikaans, and English, has a great number of particle verbs, also called separable complex verbs, which are composed of two elements: a base verb and a particle. Many linguists (e.g., Booij, 1990; De RooyBronkhorst, 1980; Haegeman \& van Riemsdijk, 1986) take these verb-particle combinations to be phrasal constructions; in particular, they are taken to be minimal verb projections (e.g., Haegeman \& van Riemsdijk, 1986). Simply put, they are entities whose syntactic status lies between simple verbs and full verb phrases. In the Dutch orthography, verb-particle constructions are written as one word when the particle and the verb are adjacent (compare Dutch opdraaien to English wind up). Verb-particle combinations behave as phrases in that the particle and the verb can be separated by syntactic rules. For example, Dutch has a rule applying to main clauses that moves the tensed verb into a position preceding the particle (e.g., Haegeman \& van Riemsdijk, 1986; Koster, 1975). The particle precedes the verb in embedded clauses such as "dat we de grammofoon opdraaien" ("that we wind up the gramophone"), but the verb is moved to a preceding position in main clauses such as "draai de grammofoon op" ("wind up the gramophone"), leaving the particle behind. The order exhibited in embedded clauses is taken to reflect the "underlying" order, and the order in main clauses is related to this underlying order by a transformation.

The semantic interpretation of verb-particle combinations is often not simply a combination of the meanings of the particle and the verb (e.g., Bierwisch \& Schreuder, 1992). Therefore, verb-particle combinations have to be listed in the mental lexicon. The mixture of phrasal and lexical properties possessed by verb-particle combinations makes them an attractive starting point for examining the mode by which the morphophonological form of phrasal constructions is planned. For example, the linear order of the morphemes in Dutch verb-particle combinations can be changed without creating another lexical item. This allows an investigation of effects of linear order independently from the ordered constituents themselves. This is not possible with words such as compounds or prefixed words, whose constituent morphemes have a fixed order.

The particle and verb of verb-particle combinations are not only separate syntactic entities but also phonological words of their own. This means that the particle and the verb are, to a large extent, phonologically independent of each other (e.g., Goldsmith, 1990; Spencer, 1991). Phonological words correspond to domains of syllabification and of stress assignment. Given that the particle and the verb of verbparticle combinations are separate syntactic entities and independent phonological words, they are good candidates for parallel planning. If empirical evidence is obtained that suggests that the particle and the verb are nevertheless planned in serial order, this would provide strong support for rightward planning of simple phrasal forms.

WEAVER ++ uses morphologically decomposed lexemes in storing verb-particle combinations, prefixed words, and compounds (Roelofs, 1996b, 1996c). However, although prefixed words and compounds are represented by a single lemma node at the syntactic level, verb-particle combinations like opgeven (give up) are represented by two lemma nodes, one representing the particle (op) and one representing the verb-particle combination (opgeven). The combination needs its own lemma node rather than sharing it with the isolated verb (geven), because the syntactic valency of the combination may differ from that of the verb alone. For example, the isolated verb geven (give) takes two 
arguments (theme-direct object and goal-indirect object), whereas opgeven (give up) takes only one (theme-direct object). In producing a verb-particle construction (see Figure 1), the lemma retriever recovers the two lemma nodes from memory and makes them available for syntactic encoding processes. These syntactic processes determine the order of the particle and verb in the utterance depending on the mood (e.g., infinitive, imperative). In the next processing step, morphological encoding, the two lemmas are mapped onto the corresponding morpheme nodes. For example, in producing the infinitive opgeven, the morpheme nodes 〈op〉, (geef\}, and $\langle e n\rangle$ are activated and successively selected. The phonological encoder takes these morphemes and produces two phonological word representations $(\omega)$, describing the grouping of segments into syllables $(\sigma)$ and the stress pattern (represented by metrical feet, $\Sigma$ ). Finally, the phonetic encoder takes these phonological word representations and produces the corresponding motor programs, which specify the articulatory gestures.

\section{Overview of the Experiments}

I present a series of implicit priming experiments testing predictions from WEAVER ++ about the production of

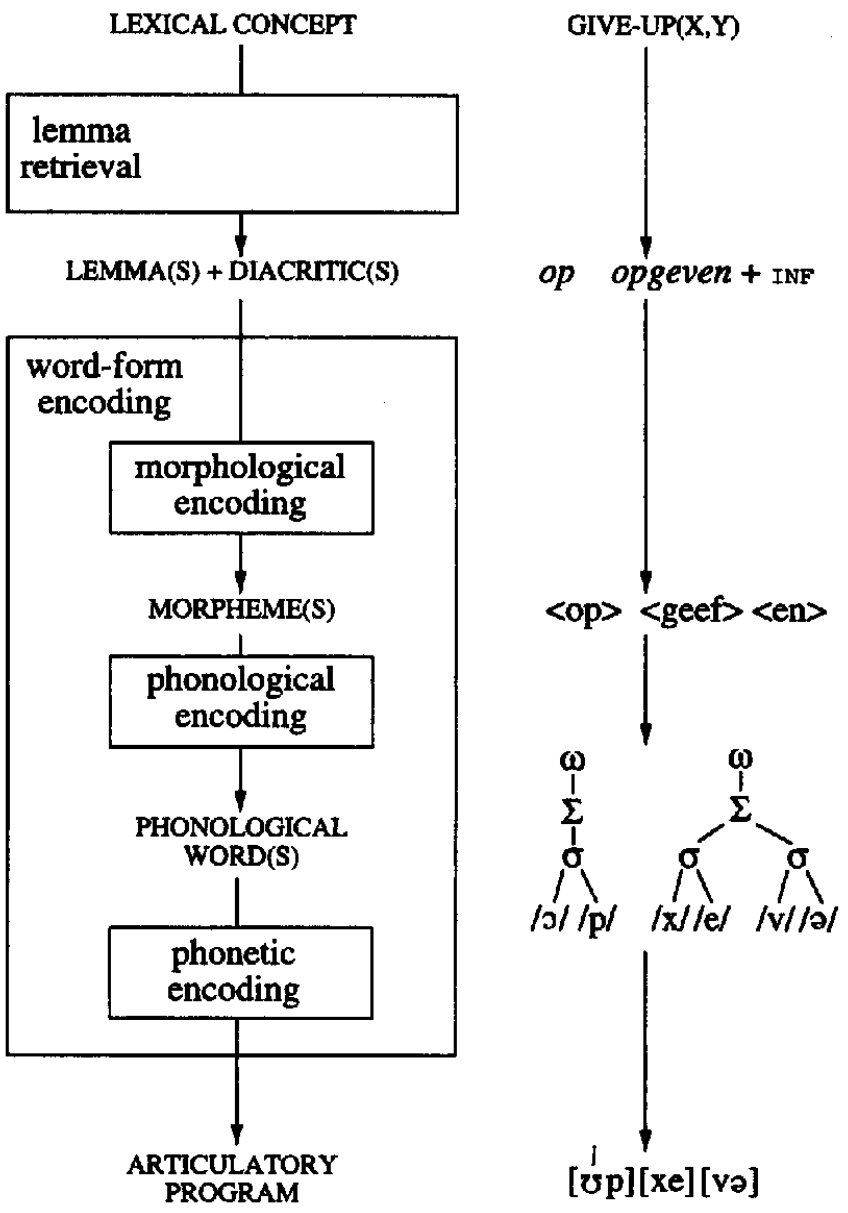

Figure 1. Planning stages in WEAVER ++ . verb-particle constructions. The predictions concern the effect of linear position, length, frequency, and repetition.

First, WEAVER + + predicts an effect of linear position. Only initial fragments should yield facilitation, because of the suspend-resume mechanism. For example, sharing the particle op (up) in the set opzoeken, opgeven, opdraaien (look up, give up, wind up) should yield facilitation, but sharing the verb zoeken in opzoeken, uitzoeken, afzoeken (look up, sift out, search) should not. Particle-initial forms will be compared with verb-initial forms. For example, sharing the verb zoek in zoek op, zoek af, zoek uit ("look up," "search," "sift out") should now produce facilitation, but sharing the particle op in zoek op, draai op, geefop (look up, turn up, give up) should not.

Second, WEAVER ++ predicts an effect of length. The facilitatory effect should become larger when the length of the shared fragment increases, also because of the suspendresume mechanism. For example, sharing the particle and the first verb syllable like uitle in uitlezen, uitlenen, and uitleven (finish, lend out, realize oneself) should produce a larger effect than sharing the particle uit only as in uitzoeken, uitdraaien, and uitgeven (sift out, turn off, publish). Also, the effect should become larger when the number of segments in the particle increases. For example, the effect should be larger for particles comprising three segments like door in doorschieten, doorzetten, doortrekken (overshoot, carry through, flush) than for particles comprising two segments like aan in aanschieten, aanzetten, aantrekken (visit, turn on, put on).

Third, WEAVER ++ predicts a frequency effect. In the model, verification times vary as a function of the frequency of the item, so that different items take different periods of encoding time within the network. This leads to the prediction that shared fragments of low frequency should yield more facilitation than shared fragments of high frequency. Low-frequency items are verified more slowly, so they should observe a greater benefit when prepared. For example, the effect should be larger for veeg (low frequency) in veeg op (clean up) than for geef (high frequency) in geef op (give up).

Fourth, WEAVER + + predicts that the facilitatory effects are independent of response repetition. If the effects are due to the suspend-resume mechanism, they should not depend on how often an item is produced. For example, preparation of noninitial fragments cannot be learned in the course of an experiment.

The remainder of the article is organized as follows: First, I report seven experiments testing the assumption of rightward incrementality. Next, I show that a simple parameterization accounts quantitatively for the results. I conclude with a general discussion.

\section{Experiment 1}

In this experiment, the responses were verb-particle combinations in a trisyllabic infinitive form with the particle preceding the verb, as in opzoeken (look up). The experiment compared the effect of sharing the particle to that of sharing the verb. The rightward incrementality of WEAVER ++ 
predicts that it should be possible to prepare the particle but not the verb. Thus, a facilitatory effect is predicted for the particles but not for the verbs. The experiment used trisyllabic forms of verb-particle combinations with highfrequency monosyllabic particles and disyllabic forms of verbs of lower frequency, so that this prediction received a strong test. Long low-frequency items are planned more slowly, so they should observe a greater benefit when primed. Thus, a facilitatory effect from preparing lowfrequency disyllabic verbs should be larger than from preparing high-frequency monosyllabic particles. However, contrary to this, the model predicts a facilitatory effect for the particles but no such effect for the verbs.

\section{Method}

Participants. All experiments were conducted with paid participants from the pool of participants collected by the Max Planck Institute. All participants were native speakers of Dutch. None of the participants took part in more than one experiment. Experiment 1 was carried out with 24 participants.

Materials and design. The materials for all experiments were obtained by an exhaustive search of the Dutch part of the CELEX lexical database (Baayen, Piepenbrock, \& van Rijn, 1993). Each response was coupled with a prompt that the author and the experimenter considered a strong and unambiguous retrieval cue for the corresponding target. For example, licht (light) was chosen as a prompt for the response uitdraaien (turn out). All prompts were nouns and all responses were verb-particle constructions. The materials of Experiment 1 consisted of four practice sets and 12 experimental sets of three prompt-response pairs each. The responses were verb-particle combinations in an infinitive form consisting of all nine possible combinations of three particles (op, af, uit) and three verbs (zoeken, geven, draaien). The mean frequency of occurrence of the particles and verbs was, respectively, 8,047 and 754 per million. Table 1 lists the response sets.

Each set was tested in a separate block of trials. In six experimental sets (the homogeneous sets) the responses shared part of their form, and in the remaining six sets (the heterogeneous sets) there was no overlap. Following Meyer $(1990,1991)$, I refer to the homogeneity variable as context. The same prompt-response pairs were tested in the homogeneous and heterogeneous condition; only their combination into sets differed. In three homogeneous sets, the responses shared the particle and in the other three homogeneous sets they shared the verb. I refer to sharing the particle or the vert as location of overlap (i.e., particle, verb).

The order of sets was rotated across participants in the following way. For 12 participants (Groups A and B) the homogeneous sets shared the particle and for the remaining 12 participants (Groups $\mathrm{C}$ and D) the homogeneous sets shared the verb. Groups $A$ and $C$ were first tested on the homogeneous sets and then on the heterogeneous sets. For Groups B and D, the order of testing homogeneous and heterogeneous sets was reversed. The sets of the two context conditions were tested in three successive sections (one third) of the experimental session. I refer to this as set repetition. A different order of the three sets of a particular context condition was used for each participant within a group, and for each repetition (section) such that each set was tested once as the first, second, and third set.

Each of the three prompt-response pairs of a set was tested six times within a block of trials. In all experiments, the order of testing the pairs was random, except that immediate repetitions of pairs were excluded. A different order was used for each block of trials and each participant.

Procedure and apparatus. All participants were tested individually. They were seated in a quiet room in front of a computer screen (NEC Multisync30) and a microphone (Sennheisser ME40). After the participant had read the instructions, the practice blocks were administered followed by the experimental blocks. In the learning phase before each block, the pairs of a set were presented on the screen. As soon as the participant indicated having studied the pairs sufficiently, the experimenter started the test phase. The structure of a trial was as follows. First, the participant saw a warning signal (an asterisk) for $500 \mathrm{~ms}$. Next, the screen was cleared for $500 \mathrm{~ms}$, followed by the display of the prompt (the noun) for $1,500 \mathrm{~ms}$. The asterisk and prompt were presented in white on a black background. On presentation of the prompt, the participant produced the corresponding verb-particle combination. For example, when the prompt licht (light) appeared on the computer screen, the participant said uitdraaien (turn out) as fast as possible while trying to make no mistake. Finally, before the start of the next trial there was a blank interval of $500 \mathrm{~ms}$. Thus, a trial lasted $3 \mathrm{~s}$. The experiment was controlled by a Hermac 386 SX computer.

Analyses. After each trial, the experimenter coded the response for errors. Experimental sessions were recorded on audiotape by a Sony DTC55 DAT recorder. The recordings contained the participant's speech and tones indicating the onset of the prompt $(1 \mathrm{kHz})$ and the moment of the triggering of the voice key $(2.5 \mathrm{kHz})$. These

Table 1

\begin{tabular}{|c|c|c|}
\hline $\begin{array}{c}\text { Location } \\
\text { of overlap }\end{array}$ & Context & Set \\
\hline Particle & Homogeneous & $\begin{array}{l}\text { Set 1: opzoeken, opdraaien, opgeven (look up, wind up, give up) } \\
\text { Set 2: afzoeken, afdraaien, afgeven (search, show, deliver) } \\
\text { Set 3: uitzoeken, uitdraaien, uitgeven (sift out, turn out, spend) }\end{array}$ \\
\hline Particle & Heterogeneous & $\begin{array}{l}\text { Set 4: opzoeken, afdraaien, uitgeven } \\
\text { Set 5: opdraaien, afgeven, uitzoeken } \\
\text { Set 6: opgeven, afzoeken, uitdraaien }\end{array}$ \\
\hline Verb & Homogeneous & $\begin{array}{l}\text { Set 7: opzoeken, afzoeken, uitzoeken } \\
\text { Set 8: opdraaien, afdraaien, uitdraaien } \\
\text { Set 9: opgeven, afgeven, uitgeven }\end{array}$ \\
\hline Verb & Heterogeneous & $\begin{array}{l}\text { Set 10: opzoeken, afdraaien, uitgeven } \\
\text { Set 11: opgeven, afzoeken, uitdraaien } \\
\text { Set 12: opdraaien, afgeven, uitzoeken }\end{array}$ \\
\hline
\end{tabular}

Note. Approximate English translations are given in parentheses. 
tones were also heard by the experimenter (via closed headphones) on each trial. The recordings were consulted after the experiment when the experimenter was in doubt about whether a response was fully correct. Four types of incorrect responses were distinguished. First, a participant might have produced a wrong utterance. Second, the response might have exhibited a disfluency, that is, the participant stuttered, paused within the utterance, or repaired the utterance. Third, the voice key might have been triggered by a nonspeech sound (noise in the environment or a smacking sound produced by the lips or tongue). Fourth, the participant might have failed to respond within a time-out period of $1,500 \mathrm{~ms}$. Incorrect responses were excluded from the statistical analysis of the production latencies. The production latencies and error rates were submitted to by-subject $\left(F_{1}\right)$ and by-item $\left(F_{2}\right)$ analyses of variance with context and set repetition as repeated measures variables and location of overlap as between-subject factor. No significant main effect or interaction was obtained for the error rates in any experiment. Therefore, I only report the means but not the test statistics for the error rates.

\section{Results}

Table 2 gives the mean production latencies in milliseconds and the error percentages for context by location of overlap for Experiment 1. The table shows that facilitation was obtained for sharing the particle but not for sharing the verb. Main effects were obtained for context (means for the homogeneous and heterogeneous sets were 624 and $642 \mathrm{~ms}$, respectively); $F_{1}(1,20)=7.89, M S E=13,825, p<.01$; $F_{2}(1,16)=18.12, M S E=502, p<.001$, and set repetition (means for the first, second, and third repetition were 672, 628 , and $600 \mathrm{~ms}$, respectively); $F_{1}(2,40)=37.66, M S E=$ $14,917, p<.001 ; F_{2}(2,32)=185.83, M S E=252, p<$ .001 , but not for location of overlap (means for the particle and verb condition were 649 and $617 \mathrm{~ms}$, respectively); $F_{1}(1,20)<1, M S E=497,585, p>.43 ; F_{2}(1,16)=8.09$, $M S E=3,192, p<.01$. In analyses of simple effects, the effect of context was significant for the particles, $F_{1}(1,10)=$ $10.24, M S E=19,182, p<.009 ; F_{2}(1,6)=26.67, M S E=$ $614, p<.002$, but not for the verbs, $F_{1}(1,10)<1, M S E=$ $8,469, p>.80 ; F_{2}(1,6)<1, M S E=370, p>.73$. There was no triple interaction between location of overlap, context, and set repetition, $F_{1}(2,40)=1.06, M S E=7839$, $p>.35 ; F_{2}(2,32)=1.78, M S E=390, p>.18$.

The means in the two heterogeneous context conditions were not the same, contrary to what one might have expected. However, because the groups of participants

Table 2

Mean Production Latencies (in Milliseconds) and Error Percentages for Experiment 1 (Particle-Initial Infinitives)

\begin{tabular}{lccc}
\hline \multirow{2}{*}{$\begin{array}{c}\text { Location } \\
\text { of overlap }\end{array}$} & Homogeneous & Heterogeneous & Difference \\
\cline { 2 - 4 } Particle & & & \\
$M$ & 631 & 666 & -35 \\
$\%$ error & 3.1 & 2.5 & \\
Verb & & 618 & -2 \\
$M$ & 616 & 2.7 & \\
$\%$ error & 2.0 & & \\
\hline
\end{tabular}

differed for the location of overlap conditions, this might simply reflect a difference in basic processing speed between participants.

\section{Experiment 2}

In this experiment, the responses were the same verbparticle combinations as in Experiment 1, but this time they were produced in an imperative form. Now the utterance consisted of a monosyllabic verb form followed by a particle, as in zoek op (look up). The experiment compared the effect of sharing the particle to that of sharing the verb. According to the model, it should now be possible to prepare the verb but not the particle. Thus, facilitation should be obtained for the verbs but not for the particles.

It is important to note that the facilitatory effect for the verbs in Experiment 2 was expected to be greater than the effect for the particles in Experiment 1. Long low-frequency items are planned more slowly, so they should observe a greater benefit when primed. Thus, the facilitatory effect from preparing long low-frequency monosyllabic verb forms should be larger than from preparing short high-frequency monosyllabic particles. The verb syllables contained three segments, whereas the particle syllables contained two segments. The prediction of an effect of length in terms of number of segments is nontrivial. Meyer $(1990,1991)$ observed an effect of number of shared syllables but did not find an effect of number of segments in a fully shared syllable. Experiment 6 independently tested for an effect of number of segments in a fully shared syllable while keeping frequency constant. In addition, the current experiment should exhibit an effect of frequency. Whereas highfrequency items typically have an advantage over lowfrequency ones (e.g., Jescheniak \& Levelt, 1994), the model predicts that the contribution of frequency in Experiment 2 will be exactly the opposite. Experiment 7 independently tested for an effect of frequency while keeping length constant.

\section{Method}

The method of this experiment and all later ones was identical to that of Experiment 1 except where noted. Experiment 2 was carried out with 24 participants. The verb-particle combinations of Experiment 1 this time had to be produced in a verb-initial imperative form.

\section{Results and Discussion}

Table 3 gives the mean production latencies in milliseconds and the error percentages for context by location of overlap for Experiment 2. The table shows that facilitation was obtained for sharing the verb but not for sharing the particle. Main effects were obtained for context (means for the homogeneous and heterogeneous sets were 638 and 690 $\mathrm{ms}$, respectively); $F_{1}(1,20)=40.30, M S E=20,998, p<$ $.001 ; F_{2}(1,16)=118.57, M S E=595, p<.001$, and set repetition (means for the first, second, and third repetition were 694,662 , and $637 \mathrm{~ms}$, respectively); $F_{1}(2,40)=42.43$, $M S E=7,615, p<.001 ; F_{2}(2,32)=61.91, M S E=435$, $p<.001$, but not for location of overlap (means for the 
Table 3

Mean Production Latencies (in Milliseconds) and Error Percentages for Experiment 2 (Verb-Initial Imperatives)

\begin{tabular}{lccc}
\hline \multirow{2}{*}{$\begin{array}{c}\text { Location } \\
\text { of overlap }\end{array}$} & \multicolumn{3}{c}{ Context } \\
\cline { 2 - 4 } & Homogeneous & Heterogeneous & Difference \\
\hline Particle & & & \\
$M$ & 672 & 685 & -13 \\
$\%$ error & 3.2 & 4.1 & \\
Verb & 604 & 694 & -90 \\
$M$ & 604 & 4.1 & \\
$\%$ error & 3.3 & & \\
\hline
\end{tabular}

particle and verb condition were 679 and $649 \mathrm{~ms}$, respectively); $F_{1}(1,20)=1.07, M S E=270,546, p>.31 ; F_{2}(1$, 16) $=9.63, M S E=2,507, p<.007$. In analyses of simple effects, the effect of context was significant for the verbs, $F_{1}(1,10)=44.38, M S E=29,277, p<.001 ; F_{2}(1,6)=$ $272.89, M S E=397, p<.001$, but not for the particles, $F_{1}(1$, $10)=2.04, M S E=12,718, p>.10 ; F_{2}(1,6)=5.03$, $M S E=430, p>.06$. There was no triple interaction between location of overlap, context, and set repetition, $F_{1}(2,40)=1.64, M S E=4,982, p>.20 ; F_{2}(2,32)=2.31$, $M S E=296, p>.15$.

To summarize, in producing Dutch verb-particle combinations in a particle-initial infinitive form, a facilitatory effect was obtained for homogeneity of the particles but not for homogeneity of the verbs. By contrast, in producing these verb-particle combinations in a verb-initial imperative form, facilitation was obtained for the verbs but not for the particles. The facilitatory effect was smaller for the particleinitial condition ( $35 \mathrm{~ms}$ ) than for the verb-initial condition $(90 \mathrm{~ms})$. This $55-\mathrm{ms}$ difference in facilitation was statistically significant, by subjects $t(20)=-3.16, M S E=24,229$, $p<.005$; by items $t(16)=-6.85, M S E=6,902, p<.001$.

The difference in the amount of facilitation between the particles and verbs in first position was attributed to their length and frequency. Before I independently tested for effects of length and frequency, other theoretical possibilities had to be excluded. First, the mood of the verbs differed between particle-initial opzoeken and verb-initial zoek op: infinitive versus imperative, respectively. Second, in the case of opzoeken, the nonoverlapping second phonological word consisted of two syllables, whereas for zoek op it consisted of a single syllable only.

\section{Experiment 3}

According to many linguists, the linear order of the particle and verb in an infinitive form like opzoeken is the underlying order. The imperative form zoek op is derived from this underlying form by means of a transformation, namely movement of the verb from second to first position. Perhaps actual language production proceeds with transformations. If the verb movement itself takes time and can be prepared for imperative forms, this may explain the difference in facilitation between the verbs and the particles. This movement account implies that the production latency of verb-particle combinations in the infinitive form should be faster than the production latency of these verb-particle combinations in the imperative form. By contrast, the infinitive and the imperative forms may be derived by ordering the particle and verb lemmas directly, for instance, along lines of syntactic encoding proposed by De Smedt (1990), Kempen and Hoenkamp (1987), or Levelt (1989). On this latter account, it is predicted that the production latency is the same for the infinitive and the imperative form of the verb-particle combination. Experiment 3 tested the movement account by comparing the production latency of the infinitive and the imperative form of a verb-particle combination.

\section{Method}

The sensitivity of voice keys differs between vowels and consonants (e.g., Pechmann, Reetz, \& Zerbst, 1989). In the previous experiments, this was controlled for by using each response as its own control (e.g., each response occurred both in the homogeneous and the heterogeneous condition). However, in directly comparing the production latencies of the infinitive and the imperative form of a verb-particle combination, the same control was not possible. The infinitives in Experiment 1 began with a vowel, and the imperatives in Experiment 2 began with a consonant. Thus, these materials could not be used in the current experiment, and a new group of nine pairs was chosen. These nine pairs were used to create three imperative sets and three infinitive sets. All sets were segmentally heterogeneous, that is, the responses in a set did not share part of their form. The responses were selected from CELEX such that, across materials, the imperative and the infinitive forms began with the same segments. Note that the initial-segment matching was between items of different sets (i.e., between items in imperative and infinitive sets), thus segments were matched across the group of materials as a whole. The Appendix lists the response sets.

The experiment was carried out with 12 participants. Six participants were first tested on the imperative sets, then on the infinitive sets. For the remaining six participants, the order of testing imperative and infinitive sets was reversed. So, the design of the experiment included only half of that of Experiment 1.

\section{Results and Discussion}

The mean production latencies for the infinitive and imperative forms were respectively 682 and $686 \mathrm{~ms}$. No main effect of mood was obtained, $F_{1}(1,10)<1, M S E=$ $5,351, p>.50 ; F_{2}(1,8)<1, M S E=2,488, p>.77$. There was a main effect of set repetition (means for the first, second, and third repetition were 728,674 , and $652 \mathrm{~ms}$, respectively); $F_{1}(2,20)=29.23, M S E=11,078, p<.001$; $F_{2}(2,16)=52.59, M S E=513, p<.001$. Mood and set repetition did not interact, $F_{1}(2,20)=1.5, M S E=7,523$, $p>.24 ; F_{2}(2,16)=10.91, M S E=86, p<.001$. The error rates for the infinitives and the imperatives were $2.0 \%$ and $2.8 \%$, respectively.

The results are compatible with the idea that the imperative and the infinitive forms of a verb-particle combination are produced by directly ordering the lemmas rather than by deriving the order of the imperative form indirectly from an underlying infinitive order. The mood of the verb-particle combination itself cannot explain or could not have contrib- 
uted significantly to the difference in facilitation between the particles and verbs in Experiments 1 and 2. The possibility that transformation of an underlying form may affect production measures has also been investigated by Bock, Loebell, and Morey (1992). These authors concluded that language production does not proceed with "mediated mappings" (with transformations), in agreement with the current findings. Of course, it remains possible that derivations take place but cannot be detected. Still, the current experiment shows that derivations cannot account for the difference in facilitation between the particles and verbs in Experiments 1 and 2 . If derivations cannot be detected, they cannot have caused the difference.

\section{Experiment 4}

An alternative hypothesis is that the difference in facilitatory effect between the particles and the verbs in initial position is due to the size of the nonoverlapping second phonological word in the utterance. The verbs in the particle-initial utterances were disyllabic, whereas the particles in the verb-initial utterance were all monosyllabic. Participants may have started articulating the verb on appearance of the prompt, relying on the possibility that they would have determined the correct particle by the time they had finished articulating the verb. This may occur more often when participants need less time to plan the remainder of the utterance while articulating, that is, more often for the condition sharing the verb than for the condition sharing the particle. The earlier initiation of articulation would then explain the increased facilitation. Experiment 4 tested whether the size of the second phonological word explains the difference in effect between opzoeken and zoek op. This was done by combining the particles from Experiments 1 and 2 (i.e., op, af, uit) with monosyllabic verbs such as doen, zien, and gaan instead of the disyllabic verbs zoeken, geven, and draaien. If the size of the second phonological word is irrelevant (as it should be according to the WEAVER ++ model), then opdoen, opzien, and opgaan (gain, look up to, go up) should yield the same amount of facilitation as sharing op in opzoeken, opgeven, and opdraaien (i.e., about $30 \mathrm{~ms}$ ). If the size of the second phonological word is responsible for the difference in effect between particles and verbs, sharing op in opdoen, opzien, and opgaan should yield the same amount of facilitation as sharing zoek in zoek $o p$, zoek af, and zoek uit (i.e., about $90 \mathrm{~ms}$ ).

\section{Method}

The experiment was carried out with 18 participants. Nine participants were first tested on the homogeneous sets, then on the heterogeneous sets. For the remaining 9 participants, the order of homogeneous and heterogeneous sets was reversed. There were six sets. In three homogeneous sets, the responses shared the particle and in the remaining heterogeneous sets they did not. The Appendix lists the response sets.

\section{Results and Discussion}

The mean production latencies for the homogeneous and heterogeneous conditions were respectively 620 and $647 \mathrm{~ms}$.
This 27-ms facilitation for context was significant, $F_{1}(1,16)=8.44, M S E=21,818, p<.01 ; F_{2}(1,6)=42.58$, $M S E=240, p<.001$. Also, a main effect was obtained for set repetition (means for the first, second, and third repetition were 667,625 , and $608 \mathrm{~ms}$, respectively); $F_{1}(2,32)=$ 9.34, $M S E=31,395, p<.001 ; F_{2}(2,12)=85.14, M S E=$ $191, p<.001$. Context did not interact with set repetition, $F_{1}(2,32)<1, M S E=8,405, p>.69 ; F_{2}(2,12)<1, M S E=$ $349, p>.62$. The error rates for the homogeneous and heterogeneous conditions were $2.8 \%$ and $2.9 \%$, respectively.

The size of the facilitatory effect for sharing op in opdoen, opzien, and opgaan (i.e., $27 \mathrm{~ms}$ ) was about the same as for sharing op in opzoeken, opgeven, and opdraaien (i.e., $35 \mathrm{~ms}$ ) and was much less than the size of the facilitatory effect from sharing zoek in zoek op, zoek af, and zoek uit (i.e., 90 $\mathrm{ms}$ ). This suggests that the size of the nonoverlapping second phonological word is irrelevant and that this size cannot explain the difference in facilitatory effect between the particles and the verbs in Experiments 1 and 2.

\section{Experiment 5}

As in the phrase and sentence production experiments of Meyer (1996), the absence of the facilitatory effect for the verbs and particles in second position (i.e., zoeken in opzoeken and op in zoek op) in Experiments 1 and 2 does not necessarily imply that there was no preparation of these items. The particles and the verbs in the first position of the utterances were independent phonological words. Claims have been made in the literature that the phonological word is the minimal unit of articulation (e.g., Levelt, 1989), though not necessarily an obligatory unit of articulation. Articulation may have been initiated on completion of this first phonological word in the utterance (i.e., op in opzoeken and zoek in zoek op). If this was the case, the speech onset latencies simply would not reflect the preparation of the second phonological word, even when such preparation would actually have occurred. Experiment 5 examined this possibility.

Participants had to produce verb-particle combinations in a particle-initial infinitive form. The particles were the same ones as in Experiments 1 and 2. However, now the responses not only shared the particle syllable but also the first verb syllable. If articulation is initiated on completion of the first phonological word (i.e., the particle), or a critical fragment of it, sharing the first verb syllable should not increase the amount of facilitation relative to sharing the particle only (Experiment 1). By contrast, if the initiation of articulation depends on planning the second phonological word, then the effect size should be larger when both the particle and first verb syllable are shared than when only the particle syllable is shared.

\section{Method}

The experiment was carried out with 12 participants. Six participants were first tested on the homogeneous sets, then on the heterogeneous sets. For the remaining 6 participants, the order of testing homogeneous and heterogeneous sets was reversed. There 
were six sets. In the three homogeneous sets, the responses shared the particle and the first verb syllable and in the three heterogeneous sets they did not. The Appendix lists the response sets.

\section{Results and Discussion}

The mean production latencies for the homogeneous and heterogeneous conditions were, respectively, 593 and 664 ms. This 71-ms facilitation effect of context was significant, $F_{1}(1,10)=20.03, M S E=40,194, p<.001 ; F_{2}(1,6)=$ 229.77, $M S E=292, p<.001$. Also, a main effect of set repetition was obtained (means for the first, second, and third repetition were 662,620 , and $603 \mathrm{~ms}$, respectively); $F_{1}(2,20)=22.19, M S E=8,909, p<.001 ; F_{2}(2,12)=$ $69.20, M S E=238, p<.001$. Context and set repetition did not interact, $F_{2}(2,12)=13.24, M S E=141, p<.001 ; F_{1}(2$, $20)=1.77, M S E=12,612, p>.19$. The error rates for the homogeneous and heterogeneous conditions were $1.8 \%$ and $2.1 \%$, respectively.

The facilitatory effect was smaller for the particles (35 $\mathrm{ms}$ ) than for the particles plus verb fragment $(71 \mathrm{~ms})$. This 36-ms difference in facilitation was significant, by subjects $t(20)=1.86, M S E=29,688, p<.05$; by items $t(16)=$ $4.43, M S E=438, p<.001$. In conclusion, the results show that in producing verb-particle combinations in a particleinitial infinitive form, the facilitatory effect is larger when the responses share both the particle syllable and first verb syllable than when only the particle syllable is shared. This suggests that planning (a critical part of) the second phonological word (the verb) determines the initiation of articulation rather than planning the first phonological word (the particle) only. Preparation of a noninitial verb syllable can be detected.

\section{Experiment 6}

For particle-initial infinitives, facilitation was obtained when the responses shared the particle but not when they shared the verb (Experiment 1). By contrast, for verb-initial imperatives, facilitation was obtained for the verbs but not for the particles (Experiment 2). The facilitation was larger for the verbs than the particles. According to WEAVER + +, this difference is due to the fact that the verbs were longer and of lower frequency than the particles. Experiments 3 and 4 excluded that this difference was due to the mood or to the length of the nonoverlapping part. The next two experiments tested for the contribution of length and frequency.

Experiment 6 tested for an effect of length while keeping frequency constant. Dutch verb-particle combinations had to be produced in an infinitive form, which means that the particle preceded the verb in the utterance, as in doorschieten (overshoot). The utterances contained either short or long particles. The long particles contained one segment more than the short ones. The frequency of the long and short particles was matched.

The prediction of an effect of number of segments is nontrivial, because it contradicts Meyer (1991). She observed that the size of the facilitatory effect from sharing the first syllable of a word is independent of the size of the syllable in terms of number of segments. In the production of disyllabic words that shared the first syllable, the size of the facilitatory effect was the same for consonant-vowel (CV) and CVC syllables. On the basis of these findings, one expects that the size of the facilitatory effect will be the same for short particle syllables like aan, bij, and toe and long particle syllables like voor, weg, and door, contrary to the prediction by WEAVER ++ .

\section{Method}

The method was the same as for Experiment 1. The experiment was carried out with 24 participants. The Appendix lists the response sets. The long particles-voor [vor], CVVC; weg [weg], CVC; and door [dor], CVVC - contained one segment more than the short ones-aan [an], VVC; toe [tu], CV; and bij [bei], CVV. The frequency of the long and short particles was matched. The means are 5,515 and 5,335 per million, respectively.

\section{Results and Discussion}

Table 4 gives the mean production latencies in milliseconds and the error percentages for Context $\times$ Length for Experiment 6. Main effects were obtained for context (means for the homogeneous and heterogeneous sets were 628 and $682 \mathrm{~ms}$, respectively), $F_{1}(1,20)=35.44, M S E=$ $25,724, p<.001 ; F_{2}(1,16)=79.29, M S E=958, p<.001$, and set repetition (means for the first, second, and third repetition were 689,649 , and $626 \mathrm{~ms}$, respectively), $F_{1}(2$, $40)=42.04, M S E=10,618, p<.001 ; F_{2}(2,32)=54.24$, $M S E=686, p<.001$, but not for length (means for the short and long particle sets were 662 and $648 \mathrm{~ms}$, respectively), $F_{1}(1,20)<1, M S E=369,627, p>.69 ; F_{2}(1,16)<1$, $M S E=9,740, p>.48$. In analyses of simple effects, the effect of context was significant for both the short particles, $F_{1}(1,10)=4.86, M S E=35,424, p<.05 ; F_{2}(1,6)=9.27$, $M S E=1,548, p<.03$, and the long particles, $F_{1}(1,10)=$ $54.59, M S E=16,024, p<.001 ; F_{2}(1,6)=90.80, M S E=$ $803, p<.001$. Most important, there was an interaction between context and length. The table shows that more facilitation was obtained in the long condition $(74 \mathrm{~ms})$ than in the short condition $(33 \mathrm{~ms})$. Statistical analysis showed that this $41-\mathrm{ms}$ difference was significant, by subjects $t(20)=-2.29, M S E=25,724, p<.02$, and by items $t(16)=-3.43, M S E=958, p<.002$. In conclusion, the outcome of the experiment confirms WEAVER ++ 's predic-

Table 4

Mean Production Latencies (in Milliseconds) and Error Percentages for Experiment 6

\begin{tabular}{cccc}
\hline & \multicolumn{3}{c}{ Context } \\
\cline { 2 - 4 } Length & Homogeneous & Heterogeneous & Difference \\
\hline Short & 645 & 678 & -33 \\
$M$ & 4.6 & 3.0 & \\
$\%$ error & & 685 & -74 \\
Long & 611 & 3.4 & \\
$M$ & 4.3 & & \\
$\%$ error & & & \\
\hline
\end{tabular}


tion about the effect of length in terms of number of segments in a shared syllable.

In contrast to Meyer (1991) but in line with Experiments 1 and 2, the current experiment shows that the size of the preparation effect depends on the length of the shared syllable in terms of number of segments. This raises the question of whether the present experiments are subject to a Type I error or whether the failure to observe the effect is a Type II error. Given the nature of inferential statistics (e.g., Winer, Brown, \& Michels, 1991), it is more likely that the present effects are real.

\section{Experiment 7}

This experiment tested for an effect of morpheme frequency while keeping length constant. Participants had to produce verb-particle combinations in an imperative form, which means that the verb precedes the particle in the utterance, as in geef op (give up). The targets contained either high-frequency or low-frequency verbs.

\section{Method}

The method was the same as for Experiment 1. The experiment was carried out with 36 participants. The Appendix lists the response sets. The frequency of the high-frequency verbs was 2,011 per million and the frequency of the low-frequency verbs was 164 per million. The verbs of the verb-particle combinations were matched phonologically. Each of the high-frequency verbs had a low-frequency counterpart with segments differing in a few phonological features only. The high and low frequency verbs were combined with the same particles (i.e., op, af, uit, aan).

\section{Results and Discussion}

Table 5 gives the mean production latencies in milliseconds and the error percentages for context by frequency for Experiment 7. Main effects were obtained for context (means for the homogeneous and heterogeneous sets were 575 and $674 \mathrm{~ms}$, respectively), $F_{1}(1,32)=72.37, M S E=$ $21,620, p<.001 ; F_{2}(1,16)=169.70, M S E=512, p<$ .001 , and set repetition (means for the first, second, and third repetition were 652,617 , and $605 \mathrm{~ms}$, respectively), $F_{1}(2$, $64)=21.78, M S E=23,117, p<.001 ; F_{2}(2,32)=134.16$, $M S E=209, p<.001$, but not for frequency (means for the low-frequency and high-frequency verbs were 611 and 638 ms, respectively), $F_{1}(1,32)<1, M S E=357,947, p>.42$;

Table 5

Mean Production Latencies (in Milliseconds) and Error Percentages for Experiment 7

\begin{tabular}{lccc}
\hline & \multicolumn{3}{c}{ Context } \\
\cline { 2 - 4 } Frequency & Homogeneous & Heterogeneous & Difference \\
\hline High & 568 & 654 & -86 \\
$M$ & 3.7 & 2.4 & \\
$\%$ error & & 693 & -111 \\
Low & 582 & 3.3 & \\
$M$ & 2.9 & & \\
\% error & & & \\
\hline
\end{tabular}

$F_{2}(1,16)=4.10, M S E=3,219, p>.06$. In analyses of simple effects, the effect of context was significant for both the high-frequency verbs, $F_{1}(1,16)=83.80, M S E=$ $21,421, p<.001 ; F_{2}(1,6)=488.20, M S E=204, p<.001$, and the low-frequency verbs, $F_{1}(1,16)=99.12, M S E=$ $30,490, p<.001 ; F_{2}(1,6)=502.69, M S E=334, p<.001$. Most important, there was an interaction between context and frequency. The table shows that more facilitation was obtained in the low-frequency condition (111 ms) than in the high-frequency condition $(86 \mathrm{~ms})$. Statistical analysis showed that this 25 -ms difference was significant, by subjects $t(32)=-1.75, M S E=25,955, p<.05$, and by items $t(16)=-3.49, M S E=363, p<.005$. This differential effect was constant over repetitions; that is, there was no triple interaction between frequency, context, and set repetition: $F_{1}(2,64)<1, M S E=4,332, p>.53 ; F_{2}(2,32)<1$, $M S E=183, p>.44$.

In conclusion, the results of Experiment 7 confirm the predictions made by WEAVER ++ concerning effects of frequency. The facilitatory effect is smaller for verb-particle combinations with high-frequency verbs than for verbparticle combinations with low-frequency verbs. The effect of frequency is independent of repetition.

Frequency effects on speech production latencies have also been investigated by Jescheniak and Levelt (1994) and Roelofs (1996b). Jescheniak and Levelt observed both a lemma-based and a lexeme-based frequency effect. The lemma-based effect disappeared with repetition, whereas the lexeme-based effect was robust over repetitions. Thus, the fact that the current frequency effect did not come and go with repetition suggests that the locus of the effect is the lexeme level rather than the lemma level. Furthermore, the current effect corresponds with the robust effect of morpheme frequency for compounds observed by Roelofs (1996b).

\section{Quantitative Account of the Results}

The results of Experiments 1-7 can be summarized as follows. First, an effect of linear position was obtained in that only initial fragments yielded facilitatory effects. Second, an effect of length was obtained in that longer fragments yielded larger facilitatory effects. Third, an effect of frequency was obtained in that fragments of low frequency yielded larger facilitatory effects than fragments of high frequency. Fourth, the facilitatory effects did not come and go with repetition.

The facilitatory effects for the verb-particle constructions in Experiments 1-7 can be captured numerically by two gain parameters, length and frequency, taking the values $\boldsymbol{\beta}$ for preparing a short fragment, $\theta$ for preparing a long fragment, and $\xi$ for preparing a low-frequency fragment. Estimates for these parameters are $\beta=-32 \mathrm{~ms}$ for preparing a short fragment (less than three segments), $\theta=-76 \mathrm{~ms}$ for preparing a long fragment, and $\xi=-25 \mathrm{~ms}$ for preparing a low-frequency fragment (less than 1,000 per million).

The numerical predictions are shown in Table 6. All fragments are high-frequency except for zoek in zoek op (shared fragments are capitalized in the table, as in ZOEK 
Table 6

Mean Effect Sizes (in Milliseconds): Predicted and Observed

\begin{tabular}{lcrr}
\hline \multicolumn{1}{c}{ Fragment } & Gain & Model & Real \\
\hline OPzoeken & $\beta$ & -32 & -35 \\
opZOEKEN & & 0 & -2 \\
ZOEK op & $\theta+\xi$ & -101 & -90 \\
zoek OP & & 0 & -13 \\
OPLEven & $\theta$ & -76 & -71 \\
OPdoen & $\beta$ & -32 & -27 \\
DOORschieten & $\theta$ & -76 & -74 \\
AANschieten & $\beta$ & -32 & -33 \\
GEEF op & $\theta$ & -76 & -86 \\
VEEG op & $\theta+\xi$ & -101 & -111 \\
\hline
\end{tabular}

Note. The conditions are denoted by illustrative examples under Fragment. The estimates for the parameter values were $\beta=-32$ $\mathrm{ms}, \theta=-76 \mathrm{~ms}$, and $\xi=-25 \mathrm{~ms}$. The fit was $\chi^{2}(7)=5.62, p>$ .50 , meaning that the model does not differ statistically from the real data.

op) and veeg in veeg op, so the frequency gain $\xi$ is assigned to these latter fragments. The fragment $o p$ in opzoeken is short, so its gain is $\beta$; zoek in zoek op is long, thus its additional gain is $\theta$; the fragment ople in opleven is long, op in opdoen is short, door in doorschieten is long, aan in aanschieten is short, geef in geef op is long, and veeg in veeg $o p$ is long. The chi-square measure of fit (for latencies, see Luce, 1986; Miller \& Greeno, 1978; Townsend \& Ashby, 1983 ) was 5.62 at $7 d f$ (number of data points [10] minus number of estimated parameter values [3]), $p>.50$. This means that the predictions are statistically not different from the real data.

The parameterization demonstrates that despite crossparticipant and cross-item comparisons, the findings from the experiments are numerically very systematic. Furthermore, the parameterization demonstrates that neither length nor frequency alone is sufficient to explain the observed effects. The tests for effects of length and frequency (Experiments 6 and 7) arose from the discussion of the large preparation effect $(90 \mathrm{~ms})$ for the verbs in Experiment 2 . According to the WEAVER ++ model, both length and frequency contributed to the large effect. Experiment 6 showed that length has an effect while keeping frequency fixed, and Experiment 7 showed that frequency has an effect while keeping length fixed. To explain the large preparation effect in Experiment 2, one needs a parameter reflecting frequency, either independently of length or combining length and frequency.

\section{General Discussion}

The aim of the present research was to examine the mode of planning of the speech production system: parallel or rightward incremental. The outcomes of Experiments 1-7 support the idea that the form of an utterance is planned morphologically and phonologically from left to right rather than in parallel. The data restrict the role of parallel processing in production. For example, if the segments of an utterance are selected simultaneously like in Stemberger's (1985a) model, an effect of the number of shared segments is not to be expected (Experiments 1,2,5, and 6). Furthermore, with parallel planning, advance preparation of noninitial morphemes and segments should have been possible, but noninitial overlap did not yield any facilitatory effects (Experiments 1 and 2). Rightward incrementality in itself does also not necessarily predict the absence of facilitatory effects for noninitial overlap. One might imagine a system that in principle plans from left to right, but under special circumstances can leave some parts of the speech plan temporarily unspecified. Rather, the impossibility to plan noninitial morphophonological fragments in advance is true under the specific assumption of the suspend-resume mechanism of WEAVER ++ .

The implicit priming task may have worked against parallel influences. In contrast to normal production, speakers in the current experiments were not trying to convey a thought. Because thoughts may comprise elements that are simultaneously active, their absence may have removed one source of parallel activation. Perhaps the absence of thoughts may have contributed to the effect of location of overlap, that is, the fact that facilitation was only obtained when the particle or verb was in first position in the utterance (Experiments 1 and 2). However, it is difficult to see how the absence of thoughts could have influenced the difference in effect between the particles and verbs in first position (Experiments 1 and 2), the effect of length within a particle or verb (Experiments 1,2, and 6), and the role of repetition (Experiments 1-7).

\section{What Kind of Processing Has Been Measured?}

A crucial assumption of this article is that initiation times in the implicit priming paradigm reftect morphological and phonological planning processes rather than, for example, articulation or planning at higher levels.

Articulatory preparation (i.e., moving the articulators in the correct starting position before the trial) may contribute to the facilitation but cannot account for the full effects, as has been shown by Meyer $(1990,1991)$. First, it is unlikely that bringing the speech organs into the optimal starting position can span more than one syllable. Therefore, the extra effect of the primed second syllable observed in Meyer's experiments and the current Experiment 5 (where it was even part of the second phonological word) must be explained in a different way. Furthermore, in Meyer's experiments implicit priming effects were obtained both for word-initial and for word-internal syllable onsets (provided that the preceding syllables were also primed). That speakers are able to move their articulators in the correct starting position for the onset consonants of two successive syllables simultaneously is unlikely. In addition, articulatory preparation fails to explain effects of morpheme frequency (Experiment 7; Roelofs, 1996b) and other morphemic effects (Roelofs, 1996c). These findings suggest that, though motor preparation might contribute to the implicit priming effects, they are unlikely to be exclusively caused by it.

Planning at higher levels as the source of the segmental and morphemic facilitation can also be excluded. For 
example, sharing morphemes often implies semantic overlap, so the facilitation may reflect preparation at the semantic level. This view, however, does not explain why the presumed facilitation from semantic overlap depends on serial position. In Experiments 1 and 2, the same morphemes were tested both in initial and noninitial position. Thus, the semantic overlap was the same for both positions, but the effects differed. Furthermore, Roelofs (1996c) has shown that semantic overlap in the implicit priming paradigm yields inhibition rather than facilitation, and therefore cannot account for the facilitation obtained with implicit priming. For example, producing the word dog in a semantically homogeneous response set (dog, mouse, horse) went slower than producing it in a semantically heterogeneous set (dog, shoe, boat).

Perhaps the effects of linear position in Experiments 1 and 2 reflect an insensitivity of production latencies to preparation of any noninitial aspects of an utterance. Elsewhere it has been shown, however, that such an insensitivity does not exist.

First, segmental priming effects for noninitial syllables have been obtained when spoken primes are presented, instead of or in addition to implicit primes. When secondsyllable primes are presented during the production of a disyllabic word, these primes yield facilitation. For example, both the spoken word jofel and the spoken syllable fel facilitate the production of tafel (Meyer \& Schriefers, 1991; Roelofs, 1998). Similarly, the spoken particle op facilitates the production of zoek op (Roelofs, 1998). Thus, production latencies have been shown to be sensitive to priming of the noninitial aspects of an utterance that are central in the present article.

The argument from spoken primes presumes, of course, that these primes activate the same representations (or closely linked ones) during their comprehension as are used in producing the target. In principle, it is possible that speakers could create the effect of a spoken prime by reciting to themselves the overlapping segments repeatedly, even when those segments are not initial. But apparently they did not engage in such recitation; otherwise implicit priming of noninitial segments would have been observed. Meyer (1990, 1991) proposed that implicit priming effects arise from repeatedly reciting segments. According to her, only effects from initial overlap are obtained because reciting noninitial segments interferes with the encoding of the initial segments of the target. However, this account leaves unexplained why overlap of noninitial segments between an auditory prime and a target does not interfere but yields facilitation. In contrast, WEAVER ++ explains both the implicit and the explicit priming effects.

Second, it has been shown that whether implicit priming effects for initial segments are obtained depends on preparation of certain downstream aspects of an utterance. For example, Roelofs and Meyer (in press) have shown that facilitation for a shared first syllable of trisyllabic words is only obtained when all the responses in a set have the same stress pattern (e.g., all have main stress on the third syllable). For example, the effect of segmental overlap was assessed for response sets with a constant stress pattern such as manuscript (manuscript), madelief (daisy), machinist (engineer), makelij (making) (all responses having stress on the third syllable) and for sets having a variable stress pattern such as marine (navy), materie (matter), manuscript, madelief (first two responses having stress on the second syllable and the last two responses having stress on the third syllable). These responses share the first syllable ma. Facilitation from sharing the first syllable was obtained for the metrically constant sets but not for the metrically variable sets. According to WEAVER ++ , the metrical structure of these words is represented in their form entries in memory. The model computes phonological words for these words by integrating the metrical structures and segments during the syllabification process. WEAVER ++'s view of syllabification implies that preparation for wordinitial segments should only be possible for response words with identical metrical structure, in agreement with the empirical findings. It is important to note that the critical variable manipulated here (e.g., whether the third syllable was stressed) did not pertain to the syllable including the shared segments nor was it continuous with the shared segments.

\section{Representation of Verb-Particle Combinations}

How does WEAVER + +'s view on the representation of particle verbs relate to other proposals in the literature? Previous studies involving verb-particle combinations concerned the domain of language understanding (Frazier, 1995; Frazier, Flores d'Arcais, \& Coolen, 1993; Kempen, 1995; Schreuder, 1990; Schreuder, Grendel, Poulisse, Roelofs, \& van de Voort, 1990; Schriefers, Zwitserlood, \& Roelofs, 1991). Schreuder (1990) proposed that written verb-particle constructions are perceived via two orthographic access nodes (one for the particle and one for the verb) that are linked to a common morphological integration node. For example, for the Dutch verb-particle combination opgeven (give up), there are three orthographic nodes, op (particle node), geven (verb node), and opgeven (morphological integration node).

In a Dutch sentence, the verb and the particle can be separated by an indeterminate number of intervening words. When the verb is perceived in a main clause, a reader does not know whether it will be the verb of a verb-particle combination or it will stand alone. This will become clear when the particle is perceived. Schreuder's (1990) morphological integration node has been proposed to explain why in reading sentences such as "als ik lang moet wachten, dan geef ik de zaak op" ("if I have to wait very long, I will give up the case") versus "als ik lang moet wachten, dan geef ik de zaak aan hem" ("if I have to wait very long, I will give the case to him"), geef alone will suffice to activate the verb-particle combination opgeven in memory and to keep it active until the particle $o p$ appears. Given that the valency of the verb in a particle-verb combination may differ from that of the verb alone, the morphological integration node has to be connected to a lemma node representing the combination at the syntactic level, as present in WEAVER ++ . Alternatively, because the combination node at the lemma level is 
needed for syntactic processing anyhow, the morphological integration node at the orthographic level may not be really needed. To conclude, Schreuder's proposal describes the perception of verb-particle combinations while WEAVER + + describes their production, and the two proposals are compatible.

\section{Conclusions}

The work in this article dealt with the issue of the time course of form encoding in speech production. The aim of the research was to examine the mode of planning used by the speech production system: parallel or rightward incremental. The outcomes of the experiments support the claim of the WEAVER + + model that the form of an utterance is planned morphologically and phonologically in a rightward incremental fashion. Previous research has provided evidence that the forms of monomorphemic and polymorphemic words are planned in a rightward incremental fashion. The outcomes of the present research suggest that this also holds for the planning of simple phrasal forms such as verb-particle constructions. Whether rightward incrementality holds for planning the production of the form of more complicated structures such as complex phrases and sentences is a topic for future research.

\section{References}

Baayen, R. H., Piepenbrock, R., \& van Rijn, H. (1993). The CELEX Lexical Database [CD-ROM]. Linguistic Data Consortium, University of Pennsylvania: Philadelphia, PA.

Bierwisch, M., \& Schreuder, R. (1992). From concepts to lexical items. Cognition, 42, 23-60.

Bock, J. K., \& Levelt, W. J. M. (1994). Language production: Grammatical encoding. In M. A. Gernsbacher (Ed.), Handbook of psycholinguistics (pp. 945-984). San Diego, CA: Academic Press.

Bock, J. K., Loebell, H., \& Morey, R. (1992). From conceptual roles to structural relations: Bridging the syntactic cleft. Psychological Review, 99, 150-171.

Booij, G. E. (1990). The boundary between morphology and syntax: Separable complex verbs in Dutch. Yearbook of Morphology, 3, 45-63.

Booij, G. E. (1995). The phonology of Dutch. Oxford, England: Clarendon Press.

Butterworth, B. (1980). Some constraints on models of language production. In B. Butterworth (Ed.), Language production. Vol. 1: Speech and talk (pp. 423-459). London: Academic Press.

Caplan, D. (1992). Language: Structure, processing, and disorders. Cambridge, MA: MIT Press.

Dell, G. S. (1986). A spreading-activation theory of retrieval in sentence production. Psychological Review, 93, 283-321.

De Rooy-Bronkhorst, A. (1980). Past participle ge-deletion and the role of stress in Dutch complex verbs. In W. Zonneveld, F. van Coetsem, \& W. Robinson (Eds.), Studies in Dutch phonology. The Hague: Martinus Nijhoff.

De Smedt, K. (1990). Incremental sentence generation: A computer model of grammatical encoding (NICI Technical Report 90-01). Doctoral dissertation, University of Nijmegen, The Netherlands.

Frazier, L. (1995). Processing discontinuous lexical items, by whatever name. Cognition, 54, 357-359.
Frazier, L., Flores d'Arcais, G., \& Coolen, R. (1993). Processing discontinuous words: On the interface between lexical and syntactic processing. Cognition, 47, 219-249.

Garrett, M. F. (1975). The analysis of sentence production. In G. H. Bower (Ed.), The psychology of learning and motivation. New York: Academic Press.

Garrett, M. F. (1980). Levels of processing in sentence production. In B. Butterworth (Ed.), Language production: Vol 1. Speech and talk (pp. 177-220). London: Academic Press.

Garrett, M. F. (1988). Processes in language production. In F. J. Newmeyer (Ed.), Linguistics: The Cambridge survey (Vol. 3, pp. 69-96). Cambridge, MA: Harvard University Press.

Goldsmith, J. (1990). Autosegmental and metrical phonology. Cambridge, MA: Blackwell.

Haegeman, L., \& van Riemsdijk, H. (1986). Verb projection raising, scope and the typology of rules affecting verbs. Linguistic Inquiry, 17, 417-466.

Jescheniak, J-D., \& Levelt, W. J. M. (1994). Word frequency effects in speech production: Retrieval of syntactic information and phonological form. Journal of Experimental Psychology: Learning, Memory, and Cognition, 20, 824-843.

Kempen, G. (1995). Processing of separable complex verbs in Dutch: Comments on Frazier, Flores d'Arcais, and Coolen (1993). Cognition, 54, 353-356.

Kempen, G., \& Hoenkamp, E. (1987). An incremental procedural grammar for sentence formulation. Cognitive Science, 11, 201258.

Kempen, G., \& Huijbers, P. (1983). The lexicalization process in sentence production and naming: Indirect election of words. Cognition, 14, 185-209.

Koster, J. (1975). Dutch as an SOV language. In A. Kraak (Ed.), Linguistics in the Netherlands 1972-1973. Assen, The Netherlands: Van Gorcum.

Lashley, K. S. (1951). The problem of serial order in behavior. In L. A. Jeffress (Ed.), Cerebral mechanisms in behavior (pp. 112136). New York: Wiley.

Levelt, W. J. M. (1989). Speaking: From intention to articulation. Cambridge, MA: MIT Press.

Levelt, W. J. M. (1992). Accessing words in speech production: Stages, processes and representations. Cognition, 42, 1-22.

Luce, R. D. (1986). Response times: Their role in inferring elementary mental organization. New York: Oxford University Press.

Meyer, A. S. (1990). The time course of phonological encoding in language production: The encoding of successive syllables of a word. Journal of Memory and Language, 29, 524-545.

Meyer, A. S. (1991). The time course of phonological encoding in language production: The phonological encoding inside a syllable. Journal of Memory and Language, 30, 69-89.

Meyer, A. S. (1992). Investigation of phonological encoding through speech error analyses: Achievements, limitations, and alternatives. Cognition, 42, 181-211.

Meyer, A. S. (1996). Lexical access in phrase and sentence production: Results from picture-word interference experiments. Journal of Memory and Language, 35, 477-496.

Meyer, A. S., \& Schriefers, H. (1991). Phonological facilitation in picture-word interference experiments: Effects of stimulus onset asynchrony and types of interfering stimuli. Journal of Experimental Psychology: Leaming, Memory, and Cognition, 17, 1146-1160.

Miller, J., \& Greeno, J. G. (1978). Goodness-of-fit tests for models of latency and choice. Journal of Mathematical Psychology, 17, 1-13. 
Pechmann, T., Reetz, H., \& Zerbst, D. (1989). Kritik einer Messmethode: Zur Ungenauigkeit von voice-key Messungen. [Criticism on a method: On the inaccuracy of voice key measurements]. Sprache und Kognition, 2, 65-71.

Roelofs, A. (1992a). A spreading-activation theory of lemma retrieval in speaking. Cognition, 42, 107-142.

Roelofs, A. (1992b). Lemma retrieval in speaking: A theory, computer simulations, and empirical data (NICI Technical Report 92-08). Doctoral dissertation, University of Nijmegen, The Netherlands.

Roelofs, A. (1993). Testing a non-decompositional theory of lemma retrieval in speaking: Retrieval of verbs. Cognition, 47, 59-87.

Roelofs, A. (1994). On-line versus off-line priming of word-form encoding in spoken word production. In A. Ram \& K. Eiselt (Eds.), Proceedings of the Sixteenth Annual Conference of the Cognitive Science Society (pp. 772-777). Hillsdale, NJ: LEA.

Roelofs, A. (1996a). Computational models of lemma retrieval. In T. Dijkstra \& K. De Smedt (Eds.), Computational psycholinguistics: AI and connectionist models of human language processing, (pp. 308-327). London: Taylor \& Francis.

Roelofs, A. (1996b). Morpheme frequency in speech production: Testing WEAVER. In G. E. Booij and J. van Marle (Eds.), Yearbook of Morphology 1996 (pp. 135-154). Dordrecht, The Netherlands: Kluwer Academic Publishers.

Roelofs, A. (1996c). Serial order in planning the production of successive morphemes of a word. Journal of Memory and Language, 35, 854-876.

Roelofs, A. (1996d). WEAVER + + and other computational models of lemma retrieval and word-form encoding. Manuscript submitted for publication.

Roelofs, A. (1997a). A case for nondecomposition in conceptually driven word retrieval. Journal of Psycholinguistic Research, 26, 33-67.

Roelofs, A. (1997b). Syllabification in speech production: Evaluation of WEAVER. Language and Cognitive Processes, 12, $657-693$.

Roelofs, A. (1997c). The WEAVER model of word-form encoding in speech production. Cognition, 64, 249-284.
Roelofs, A. (1998). Parallel activation and serial selection in planning linguistic performance: Evidence from implicit and explicit priming. Manuscript submitted for publication.

Roelofs, A., \& Meyer, A. S. (in press). Metrical structure in planning the production of spoken words. Journal of Experimental Psychology: Learning, Memory, and Cognition.

Roelofs, A., Meyer, A. S., \& Levelt, W. J. M. (1996). Interaction between semantic and orthographic factors in conceptually driven naming: Comment on Starreveld and La Heij (1995). Journal of Experimental Psychology: Learning, Memory, and Cognition, 22, 246-251.

Schreuder, R. (1990). Lexical processing of verbs with separable particles. In J. van der Marle and G. Booij (Eds.), Yearbook of Morphology (Vol. 3, pp. 65-79). Dordrecht, The Netherlands: Floris.

Schreuder, R., Grendel, M., Poulisse, N., Roelofs, A., \& van de Voort, M. (1990). Lexical processing, morphological complexity and reading. In D. A. Balota, G. B. Flores d'Arcais, \& K. Rayner (Eds.), Comprehension processes in reading (pp. 125-141). Hillsdale, NJ: LEA

Schriefers, H. (1992). Lexical access in the production of noun phrases. Cognition, 45, 33-54.

Schriefers, H., Zwitserlood, P., \& Roelofs, A. (1991). The identification of morphologically complex spoken words: Continuous processing or decomposition? Journal of Memory and Language, 30, 26-47.

Spencer, A. (1991). Morphological theory. Cambridge, MA: Blackwell.

Stemberger, J. P. (1985a). An interactive activation model of language production. In A. W. Ellis (Ed.), Progress in the psychology of language (Vol. 1, pp. 143-186). London: LEA.

Stemberger, J. P. (1985b). The lexicon in a madel of language production. New York: Garland Publishing.

Townsend, J. T., \& Ashby, F. G. (1983). Stochastic modeling of elementary psychological processes. Cambridge, England: Cambridge University Press.

Winer, B. J., Brown, D. R., \& Michels, K. M. (1991). Statistical principles in experimental design. New York: McGraw-Hill. 
Appendix

\section{Responses of Experiments 3 Through 7}

Experiment 3

Mood: Infinitive

Set 1: wegdraaien, losweken, voortrekken (turn off, soak off, favor)

Set 2: rondneuzen, naroepen, meevragen (nose about, call after, invite)

Set 3: toeblaffen, doormeten, bijlichten (bark at, measure, light up)

Mood: Imperative

Set 4: draai weg, roep na, licht bij

Set 5: week los, vraag mee, blaf toe

Set 6: trek voor, neus rond, meet door

\section{Experiment 4}

Context: Homogeneous

Set 1: opdoen, opgaan, opzien (gain, go up, look up to)

Set 2: afdoen, afgaan, afzien (settle, ring, abandon)

Set 3: uitdoen, uitgaan, uitzien (take off, leave, watch)

Context: Heterogeneous

Set 4: opdoen, afgaan, uitzien

Set 5: opgaan, afzien, uitdoen

Set 6: opzien, afdoen, uitgaan

\section{Experiment 5}

Context: Homogeneous

Set 1: uitlezen, uitlenen, uitleven (finish, lend out, realize oneself)

Set 2: opdragen, opdraaien, opdraven (celebrate, wind up, fix)

Set 3: afweken, afweren, afwegen (soak off, parry, weigh)

Context: Heterogeneous

Set 4: uitlezen, opdraaien, afwegen

Set 5: uitlenen, opdraven, afweken

Set 6: uitleven, opdragen, afweren

\section{Experiment 6}

Length: Short

Context: Homogeneous

Set 1: aanleggen, aanvallen, aanbrengen (arrive, attack, apply)

Set 2: bijleggen, bijvallen, bijbrengen (settle, support, teach)

Set 3: toeleggen, toevallen, toebrengen (lose, confere upon, do)

Context: Heterogeneous

Set 4: aanleggen, bijvallen, toebrengen

Set 5: aanvallen, bijbrengen, toeleggen

Set 6: aanbrengen, bijleggen, toevallen

Length: Long

Context: Homogeneous

Set 7: voorschieten, voorzetten, voortrekken (lend, prepare, favour)

Set 8: wegschieten, wegzetten, wegtrekken (shoot away, put away, leave)

Set 9: doorschieten, doorzetten, doortrekken (overshoot, carry through, flush)

Context: Heterogeneous

Set 10: voorschieten, wegzetten, doortrekken

Set 11: voorzetten, wegtrekken, doorschieten

Set 12: voortrekken, wegschieten, doorzetten 
Appendix (continued)

\section{Experiment 7}

Frequency: High

Context: Homogeneous

Set 1: geef op, geef af, geef uit (give up, deliver, spend)

Set 2: laat op, laat uit, laat aan (fly, let out, leave on)

Set 3: maak op, maak af, maak uit (clean, finish, light up)

Context: Heterogeneous

Set 4: geef op, laat uit, maak aan

Set 5: geef af, laat aan, maak op

Set 6: geef uit, laat op, maak af

Frequency: Low

Context: Homogeneous

Set 7: veeg op, veeg af, veeg uit (clean up, wipe off, sweep out)

Set 8: ruk op, ruk aan, ruk uit (advance, order, turn out)

Set 9: meet op, meet af, meet aan (measure, measure, take someone's measure for)

Context: Heterogeneous

Set 10: veeg op, ruk uit, meet aan

Set 11: veeg af, ruk aan, meet op

Set 12: veeg uit, ruk op, meet af

Note. Approximate English translations are given in parentheses. A listing of the materials including the prompt words can be provided by Ardi Roelofs. 